\title{
Music and embodied creative space
}

\author{
Zvonimir Stephen Nagy \\ Tarleton State University
}

\begin{abstract}
This article places the compositional work of Johann Sebastian Bach in the context of present day practice of creating music. It uses images and places from the art of memory to the act of making music in order to closely examine the relationship between musical creativity and embodiment. While focusing on the central hypothesis that exposure to specific musical practices leads to the formation of multimodal creative agency, an argument is made for the emergence of an embodied creative space. The embodiment of musical creativity is defined as a cognitive and performative causality: a relationship between the cause and effect when composing, performing, or listening to music. Expanding on this model, music making is further considered to be an embodied activity that stems from the causality of these interde-pendent attributes of creativity: the cognitive actions controlled and sustained by our mind, and the performative interactions mediated by our body and the environment. By exploring the actions and interactions commonly associated with composing and performing music, this article defines the embodied creative musical space as an interactive agency that lives at the threshold of cognition and performativity. As a result, the nature of musical creativity as an embodied, lived experience extends the social and collaborative concepts of creativity, as it becomes an interactive creative contingency. Delivered from the perspective of a composer, performer, and music scholar, the paper contributes to the growing interdisciplinary discourse on musical creativity.
\end{abstract}

Keywords: musical creativity, embodiment, memory, creative space, musical composition and performance. 


\section{Before Bach}

If we were attending a symposium in ancient Rome, we would not have many note taking abilities at our disposal. We would not have portable electronic devices and apps to take notes or Moleskin type notebooks to jot down important ideas and concepts heard during the talks and presentations, much less a way to record each other's feedback, ideas or suggestions. Rather, we would have been expected to develop sophisticated skills for remembering the information we heard. Known as "the art of memory", this cognitive ability was taught as an important prerequisite in the practice of rhetoric. In order to become a successful orator or to convey important information or experience, one was trained to develop the skills to remember, by literally saving on one's mind memory hard drive various places or images that would have been analogous to the information attempting to be stored. It was the relationship between two types of images, one for things and one for words that Cicero, a Roman orator, referred to when he described the imprint of those loci and imagines, or places and images, as inner writing. This resulted in an activity that proved to be known as a type of creative rhetoric space in which, as the English historian Frances Yates (1966) documented, "the places [were] very much like wax tablets or papyrus, the images like the letters, the arrangement and disposition of the images like the script, and the delivery like the reading" (p. 7).

Despite this inner or psychological process of training one's memory skills, as I consider the above analogy, I couldn't help but think of the physical, spatial objects, regardless of their deliberate use in facilitating the art of remembering, could also signify the interactive nature of the human creative experience. Here I suggest we extend these images and places from the art of memory to the act of making music, in particular to the creative work of one of the most influential composers of Western classical music, that of Johann Sebastian Bach (1685-1750). Bach considered compositions to be musical objects, or "artfully composed things" (Bach et al., 1994, p. 66; cited in Wolff, 2000, p. 331).
In fact, I would say that Bach's musical compositions embodied both conceptual or cognitive, as well as the contextual or performative processes: Bach considered his musical pieces, or things, as if they were spatial entities. For that matter, Bach seemed to conceive of his music in a very experiential way, engaging not only in the creative action of making music but also in the creative interaction with the production and realization of his musical material. This very well may have enabled Bach to fully take advantage of his creative ideas by composing music which continues to this day to sound well crafted and fresh, while still relevant within contemporary musical culture. Given the unique creative agency that is lived experience, Bach seemed to have arranged images of musical objects in the memory of his music. This apparent interdependence between perception and cognition, movement and emotion, music and language, and interactions with the environment, invites us to consider Bach's musical creativity in a situated or embodied creative experience.

Bach composed six cello suites between 1717 and 1723. The Prelude from Bach's Suite no. 1 for unaccompanied cello in G major, BWV 1007, remains among the best-loved works in the classical music repertoire ${ }^{1}$. Perhaps one way to understand what prompted Bach to make certain decisions in his creative process is to think beyond the role of memory, and at the role that prior experience may play in creating and listening to music. What is compelling here is that some captivating attributes continue to permeate our listening experience so that no matter how many times we hear this piece, the majority of us somehow don't get tired of listening to it! Could it be that Bach composed music in a way that made him consider the interactions of larger chunks of music, as well as the melodic and harmonic units, musical schemas, or groupings of individual notes as words or images, not so different from the idea of letters introduced in the

\footnotetext{
1 The reader can access a recording of Bach's Prelude featuring the cellist Yo-Yo Ma at https://www.youtube. com/watch?v=1 prweT95Mo0
} 
earlier quote by Cicero? Or by the same token, could it be that we as listeners, through the questioning of our very sense experiences, engage in a unique form of inner or mental perception that demands from us attention and intentionality towards lived past musical situations, objects, or circumstances?

I explored these questions a while back when I wrote about the apperception of musical creativity (Nagy, 2015). The term apperception comes from the Latin, ad-: "to, toward" and percipere: "to feel, gain, learn, perceive, secure." My concern was to argue to what extent our prior experience contributes to our understanding of ritual and self-realization in musical creativity. As a multimodal or transformative process of perception, apperception concerns the attributes of the cognitive domains acquired in one's mind through prior lived experiences.

Indeed, culturally our music is one governed by our past experiences: elements of musical tradition gathered through various forms of musical education, concerning what musical information may live in one's memory. It may not come as a surprise that Descartes's saying 'Cogito ergo sum' ('I think, therefore I am') remains an important cornerstone of musicians' relationship with creativity. Could it be that if something is known, it is a made thing; it possesses a musical image or place?

\section{After Bach}

The attributes of apperception may account for the creative mechanisms and processes of creating music. Two examples are useful here. Composers today work hard on forming a musical language that resonates with audiences at various levels. For many, their compositional language and style also have a different level of novelty, that more than ever finds its place between tradition and innovation, thus suggesting the apperceptual link with prior musical experiences (Nagy, 2015). Meanwhile, performers also often unintentionally use bodily gestures and movements to convey emotion and meaning of music. This inevitably becomes contingent upon the multimodality of creative experience, suggesting a type of embodied reciprocity of actions and interactions while making music.

To illustrate this point further, it is instructive to examine a present day composer who turned to Bach's music not only as inspiration but as the main source material for his compositions. Peter Gregson (b. 1987) is a renowned Scottish cellist and avid composer. In 2008 Gregson re-leased his latest CD album, entitled Recomposed by Peter Gregson - Bach: The Cello Suites (Gregson, 2018), in which he took on Bach's six cello suites and reinterpreted, or recomposed them, so that they became completely new compositions.

Scored for solo cello and performed by Gregson himself and an ensemble of five cellos, this new take on Bach is further enhanced with a mirage of sophisticated electronic sounds, which further exemplify Bach's musical material while placing it in the context of contemporary classical music. This apparent fusion of old and new was achieved by applying a more traditional approach to using electronic synthesizers by amplifying them as if they were traditional instruments. Yet, I believe that for Gregson, as it was for Bach in his time, the art of creating music was also an art of shuffling through the memory of their prior experiences: the art of finding the creative space that would allow the composer to carve out the musical place of his composition, distill musical notes, rhythms, and harmonies from the constructed musical images, and ultimately deliver his musical creation by performing and recording it. According to Gregson, "rather than thinking about Bach's compositions as a two-dimensional painting, I thought of them as sculpture. So although the object is the same, if you turn around it and see it from a different angle - shine the light on it in a different way - you get different textures coming out; 
different shadows get cast". 2 What is more, Gregson's relationship with space also implied a more interactive or collaborative agency, in which understanding the room acoustics, the properties and placement of musical instruments, as well as relationships with other musicians and producers, played a huge part in shaping the composer's creative process. This also echoes the idea of creating in reverse introduced by a Scottish-American singer-songwriter David Byrne, when in his book How Music Works he made a persuasive argument that musicians create works that fit their intended venues and sound good to their intended audiences (Byrne, 2017).

If you compare Gregson's version of the original prelude by Bach referenced earlier, be mindful of not only the similarities, but also the differences between Bach's original score, and Gregson's new, modern rendition. As you listen to the music ${ }^{3}$, pay attention to how Gregson groups and repeats different melodic fragments into units, enabling you to experience them as if they are a series of unfolding images.

\section{Introduction to Embodied Creative Space}

I acknowledge that creativity in music, like in any other domain, must fulfill three main requirements. Musical creativity and its processes and products must be innovative and to some extent also new in their appearance. Creative musical activities and ideas and their outcomes must also be well constructed and recognized to be of the highest quality. Moreover, yet, while conceptually well made, creative music-making, regardless if it is composition or performance must be eventually contextualized in order to become relevant to the nature and purpose of music expression (Kaufman and Sternberg, 2010). I also accept that the

\footnotetext{
2 (n.d.). Retrieved from https://www.deutschegrammophon.com/us/artist/gregson/

${ }^{3}$ The reader can access a recording of Gregson's piece at https://www.youtube.com/watch?v=x|Km4TKR1/8
}

act of creativity is a psychological pursuit, in which the creative actions and processes take full advantage of cognitive and perceptual mechanisms (Sawyer, 2012). As a result, I also find the act of creativity, especially in music, to be embodied both as an active mechanism that draws on the interrelations of our body and the environment, as well as on the interactive experience of creating musical forms, objects, or products.

I wish to take the above premise and develop it further. My goal is to contribute to the growing interdisciplinary discourse on the connection between musical creativity and embodiment, extending the social and collaborative concept of creative experience. I thus invite the reader to approach this article from a more exploratory perspective as we construct what may be a new take on creativity - a formation of embodied creative space that I hope proves to be well thought of and relevant to our contemporary understanding of creative music making. Most of these topics deserve fuller treatment than I can give in this article, especially given the space and introductory nature of my topic, so my concern here is just to lay out a basic, if wide ranging argument.

As a composer and scholar, my focus is on the psychological foundation of musical creativity. In my book entitled, Embodiment of Musical Creativity: The Cognitive and Performative Causality of Musical Composition, I offered an innovative look at the interdisciplinary nature of creativity in music (Nagy, 2018). In that publication, I defined the embodiment of musical creativity as a cognitive and performative causality: a relationship between the cause and effect when composing music. I presented an argument for the psychological attributes of creative cognition whose associations become the foundation for an understanding of embodied creativity. Besides proposing a model of compositional creativity, I also developed methodologies from humanistic and scientific disciplines aimed at identifying a relationship between musical creativity and the acts of the practice and teaching of musical composition. 
As I continue to build on these ideas and concepts, I wish to look beyond this creative causality by searching what initially may have manifested itself as a creative residue, a multifaceted field of actions and interactions within a network of creative potentiality. Hence, to extend the model of the embodiment of musical creativity developed in my book, I re-examine the notion of em-bodiment as a catalyst for the emergence of creative musical space - a cognitively embodied creative space that becomes a multimodal agency, a lived creative experience that interconnects musical mind and body with the environment (Shapiro, 2017).

The issues that prompted me to explore the idea of a creative space came from two somewhat related areas of creativity research. Considered today to be very influential in shaping the discourse on how to think of creativity, they originated on opposite sides of the Atlantic. It was the multiplicity of creative manifestations common to both approaches that inspired me to think of creativity as having interactive and spatial qualities, that while singular in their conception, result in a network of interrelated creative representations and manifestations.

First, I was able to notice the multimodality of this approach in the work of Howard Gardner (2006). Based on the study of the mind and the brain, Gardner introduced the concept of multiple intelligences to describe human cognitive competence in terms of a set of abilities, talents, or mental skills. By making a case that individuals come from different backgrounds and in turn have various levels of aptitude for particular skills and their combinations, Gardner (2006) introduced a multimodal approach to creative thinking, whereby "an intelligence entails the ability to solve problems or fashion products that are of consequence in a particular cultural setting or community. The problem-solving skills allow one to approach a situation in which a goal is to be obtained and to locate the appropriate route to that goal. The creation of a cultural product allows one to capture and transmit knowledge or to express one's conclusions, beliefs, or feelings" (p. 6). Hence, Gardner offers the framework that is provided for understanding musical creativity and how it emerges from real practice across a set of different, but mutually interdependent creative abilities. Those abilities stem from real-life experiences and also involve one's attentiveness and awareness to networks of social interactions that may enhance or hinder creativity.

More recently, Burnard (2012) provided a unique appraisal of the social and cultur-al dimensions of musical creativity. Similar to Gardner, she also focused on teaching and learning creativity, while at the same time unfolding her discussion across many different musical practices and traditions. For example, a range of creative musical contexts that Burnard examined in her study included original bands, singer-songwriters, club DJs, contemporary classical composers, improvisational performers, and the interactive audio designers who create video game soundtracks. Burnard demonstrated how the behavior and practices of musicians working in widely diverse genres also embody a divergent set of musical creativities, making a strong argument that there is no one single way to be musically creative today, thus suggesting a layered representation of creativity. As Burnard (2012) suggested, this coexistence of musical creativities may be defined, "in terms of practices corresponding to music's social and technological mediations: that is, how musical creativities produce their own varied social relations in performance, in musical associations and ensembles, in the musical division of labour and in social practices" (p. 8). This approach appears to be firmly rooted in musicians' collaborative approach to creating music as well as their interactions with each other and the environment.

What is interesting to me about both Gardner and Burnard's contributions is, as noted earlier, a multilayered, almost multidimensional psychological sense of creative experience. In fact, what the models of multiple intelligences and creativities have in common is that they also imply an operational 
network, or a route as Gardner suggests, of creative actions and interactions. This allows for a creative experience that embodies a collection of creative aptitudes and predispositions, once again calling for a multiplicity of human creative abilities. Here every new creative act becomes a plateau of creative possibilities whereby music creators explore a network of creative pathways, rather than thinking of the one size fits all approach to composing or performing music.

If we think of this creative experience in more multidimensional terms, could we then talk about a creative space, not so much as a mere metaphor for this argument, but as an instance of the embodied, or if we borrow Clark's (2008) term, extended creative experience?

\section{Music and Embodied Creative Space}

Just what is creative space? What does it represent when we think of music? Is it a physical or environmental, or cognitive or mental creative space, or both? Moreover, if we talk about this creative space, are we referring to a person, process, place or product; or to all of them simultaneously? These questions may once again remind us of Csikszentmihalyi's contributions to our understanding of creativity. Exploring the psychology of creativity, he introduced what is known today as the flow model of creativity (Csikszentmihalyi, 1996). Csikszentmihalyi advocated for a synergy of awareness and action within the creative process as one of the prerequisites for this highly immersed creative experience. Does not this reciprocity of awareness and action through an almost spatial image of a flow, or a field, remind us of our discussion of the art of memory from earlier - the "projection" of images into places, as the French phenomenologists would say (MerleauPonty 2013, 15): the images of things and words, or the musical themes and notes?

When we think about the creative space experienced when making music, we may think first of the physical spaces designed to perform or listen to music. However, the very nature of the embodied musical experience points as well to the cognitive or mental spaces that are inscribed in our creative experience. This once again evokes Csikszentmihalyi’s (1993, p. 127) ideas of creative surroundings and inspiring environments, arguing for the importance of creating in the right place at the right moment (also see Csikszentmihalyi, 1988).

Perhaps another way to describe this working idea of a creative space would be a dynamic type of embodied mediation of our mind and body via musical sound, from the inside towards the outside world, a process that may contribute to the emergence of a particular creative agency when partaking in a musical act. From this perspective, I suggest that this manifestation of embodied creativeness grows out of the more situated or embodied creative space where the mind, body, and our interaction with the environment, may coexist as an integrated whole. Hence, from this phenomenological perspective, the concept of embodiment here too implies a multimodal representation of the body's relation to the self and to the world. Thus, questioning the cognitive and performative correlation of creative experience, could we propose the hypothesis that may account for the embodied contingency that forms a framework for a more dynamic nature of creative musical experience, characterized by continuous and ever changing creative activity?

Here I wish to make an argument that making music is indeed an embodied activity that forms a link that emerges from the causality of two attributes of creativity: the cognitive actions controlled and sustained by our mind, and the performative interactions mediated by our body and the environment. Considering those actions and interactions commonly associated with composing and performing music, I define the embodied creative musical space as an interactive agency that lives at the threshold of cognition and performativity. Cognition and performativity may also be seen as two sides of the same coin; one can't exist without the other. Together, they constitute that causal relationship with 
the interactive, and most importantly, a collaborative network of embodied creative experiences.

In Music as Creative Practice, Nicholas Cook makes a case for a social approach to creativity that he believes can bring a new understanding of creativity in music, an approach that, as he says, "sees an interaction between people as the core of the creative practice" (Cook, 2018, p. 11). If making music is a set of creative processes and behavioral patterns that are often shared within a group, then music making, with its actions and interactions, could certainly be placed into this creative space. I would say that in this way, the embodied creative musical space is a synergy of individualist and sociocultural approaches to creativity.

Embodied musical space is thus defined by this extended reciprocity whereby it's not only cognitive and performative causality that represent this creative space, but most importantly, it is also the interactive contingency principle within that causality that constitutes the very continuum of embodied creativity. Informed by interactive communication, the interactive contingency principle denotes a dynamic and complementary exchange of information and ideas between and among the participants. As Cook once again reminds us, this conveys, "the sense of people making music. In so doing, it figures creative practice as not just based on, but made of human actions and interactions" (Cook 2018, p. 1). This exchange between humans, and even machine or art forms, is considered active and interactive with the causality of affecting one another.

Another way to explain the interactive contingency principle is to use ideas from cognitive semantics. For example, exploring the construal operations, or how individuals perceive, comprehend, and interpret the world, one can understand how individuals structure their experience involving language formation (Croft and Cruse, 2004). I argue that by looking at what cognitive and performative operations are used in a creative endeavor, we may be able to account for how creative processes convey a sense of embodied creative space.

Having a closer look at music and embodied creative space, at its core, the field of this musical experience is an exploration of form, place, and space. As I look back to Gregson's re-evaluation of Bach's Prelude, I'm deciding to use these terms as a structure - not necessarily an instance of musical structure, but a multi leveled structural foundation of the embodied creative musical space. Seemingly interchangeable, these three words - form, place, and space, refer to nuanced elements of creating music that embodies the very act of music-making. As a practitioner and teacher of musical composition and performance, I have spent nearly all my professional life as a composer and performer thinking about these ideas, and it was relatively recently that I discovered how crucial their interconnectedness is with our sense of embodied space. Yet, because of the inherent complexities of this embodied creative experience, or as I signaled earlier in this article, of multiple creativity types, it seems fitting to spend time breaking apart the layers of this creative space, and its forms and places.

Forms and places may be seen as the unifying concept of creativity, and on their most basic level, they refer to the essence of creative activity. It is where I begin to compose or perform music; it is where musical creativity happens. It is also somewhat an ambiguous term that may refer to formal musical structure, design, and technique, or the work environment spaces intended to compose and perform music in. In fact, as the composer, Mahnkopf (2002) suggested, musical structure may unfold in four dimensions. In addition to the acoustical space, Mahnkopf distinguishes other three dimensions of linearity/horizontality (melodic dimension), planarity/verticality (harmon-ic dimension), and what he calls the front/back dimension of musical timbre (orchestration dimension). Despite this clear distinction between the two, we can also think of forms and places as image-schemata, accounting for the ways composers structure, understand, and "assemblage", as Cook may suggest, the elements of their 
experiences driven by their embodied senses. Because of that, musical forms and places may contain multiple layers of meaning, especially now, when placed in the context of creativity.

Similar to physical space that can be measured or altered, creative space can also be characterized by various levels of depth. And yet, creative space is often an intangible entity that is both dependent on and complementary to space. When musicians think of space, they may think of two creative spatialities: one related to the cognitive, mental, structural shapes and forms of the music that they're composing or performing; and the other to the process of composing or performing music within the actual work environment space where the activity is taking place. However, it is precisely a setting that one can take part in, either individually or collectively, actively or interactively, that evokes a sense of embodied creative spatiality, or for that matter, through an interplay of cognitive and performative actions and interactions. We could now also make an argument that musicians take up space by shaping musical experience and its signification. Looking at Leman's (2008) theory of embodied music cognition, we can here attest that musicians also conquer and repurpose the space by their corporeal articulation, imitation, and intentionality.

Embodied creative space is not given; it is created composed and performed: the musicians' actions and interactions define the experience of space. Creative musical space is thus a living, embodied space. In this respect, this concept of embodied creative space further resonates with Leman's theory in which the creative mediator (the body) can be extended - acted or interacted upon with human and nonhuman environmental mediators. If we consider this analogy as forming a structural network of creative endeavor, which here too can be mapped onto musical creativity, would it then also be possible to talk about creative structure as the epitome of creative space? The Oberlin Conservatory music theorist, Arnie Cox, investigated some of these issues in his recent interdisciplinary study on embodied music cognition (Cox, 2017). In it, Cox introduced what he termed the mimetic hypothesis, based on the premise of embodied imitation - the contingency of the musicians' mental and physical efforts engaged when listening, thinking, moving, and feeling music.

As a composer and performer of music myself, I am also trying to understand, reevaluate, and depict form and place in my creative work. For me, form and place interact in a consistently fluid creative space, adjusting to creativities based on my prior experiences of making and experiencing music. This embodied fluidity first requires me to work out the very fundamental structural elements to compose a piece of music, or performance technique required to perform a musical work. Secondly, and what is more important to our discussion today, an embodied sense of making music also denotes a network of interrelated creative mechanisms and processes that enable me as a composer and performer to have my unique, lived creative experience in making music. In turn, I find myself engaging in a multimodal space of creative possibilities that while dependent on a cognitive and performative causality, also allow me to enter a new realm of creative possibilities. Creative space affects the way composers and performers experience music, and as we get to know our creative space, we may shift our perception of it, forming a setting for creative exploration and discovery.

\section{Implications in Music Composition and Performance}

What are the elements and common processes a composer draws upon when making a piece of music? Composing music has become such a multi-faceted process and takes ideas about structure and content from many disciplines: mathematics, astronomy, literature, and visual arts, to name a few. As such it requires extensive mental resources and experience from the composer. Many starting points in musical creativity are often not based on sound at all; more 
and more musicians create music by interacting with physical gestures, movement, proportion, visual relationships, art, and literature. This interdisciplinary approach suggests a more interactive model of making music in which composers are not only interacting with the other composers and audiences they're composing for, but also with musical objects, such as instruments and computers, and other composition materials, which in turn become new instruments. In fact, as Cook (2018) suggests, "the materials with which composers work 'talk back' to them: in this way [we can understand creativity] in terms of the same social, network-based models" (p. 11).

Similarly, when performing, the musical instrument necessitates the kinesthetic nature of the interactive experience. It is similar to the difference between watching someone play the piano and actually playing the instrument yourself. It is only through the playing, touching, and hearing that one can experience and "feel" how the piano sounds. Again, as Gardner (2003) reminded us, "even an apparently straightforward role, like playing the violin, transcends reliance on musical intelligence. To become a successful violinist requires bodily kinesthetic dexterity and the interpersonal skills of relating to an audience and, in a different way, of choosing a manager; quite possibly it involves an intrapersonal intelligence as well" (p. 22). It may be interesting to develop a methodology that models a performer's experience of physical balance and gestures when playing the instrument. This may further situate my present inquiry in the context of embodiment and offer an object specific consideration of the relationship between performance and creativity. Indeed, having an awareness of how our mind and body interact with musical objects (and other musicians) allows the musician to network creative agency into inherently variable, adaptive actions and interactions that combine into unique and often continuously differentiated fields of creative space.

\section{Beyond Bach}

Musicians come with a variety of creative backgrounds and interests. As it becomes more often the case, it's possible for someone to start at a different place, and then gain creative fluency and proficiency in due course. It is the idea that musicians come to experience creativity with varying degrees of knowledge of the technical aspects of music: musicians are inded informed and guided by a number of different types of musical creativities (Burnard, 2012).

A few years ago, I composed a musical epigram on Bach's cello prelude, this time scored for an ensemble of four cellos, entitled Epigram Variations (Nagy, 2016). I invite the reader to listen to yet another re-composition of Bach's cello Prelude ${ }^{4}$, and to think of the interplay of musical images, objects, and notes, as well as the actions and interactions that extend the music into an embodied creative experience.

What embodied creative actions contribute to the composition and what interactions to the performance of the music? Do we hear the embodied creative space? While both creative actions and interaction played a significant role in composing the piece, one of the implications was that my compositional process turned into an expansion of Bach's original score into a new piece of music, inevitably becoming another instance of a recomposed musical work. By questioning and rethinking the given musical material, I collaborated with Bach's music by elaborating it. What is more, through careful listening, analyzing, and experimenting with the newly constructed musical structures, this creative process of recomposition also became rather experiential in nature. In turn, it became an elaboration study project on given musical schemas found in Bach's Prelude, thus invoking the cognitive aspects of creative space. On the other hand, by relentlessly searching for idiomatic performance techniques and

\footnotetext{
${ }^{4}$ The reader can access a recording at https://www.youtube.com/watch?v=qOZnhlYdlcQ
} 
practices, I was able to decide how to best score my new piece for an ensemble of four cellos. During the later stages of composing the piece and its preparation for its performance, I was able to interact with the performers, further enhancing my general approach to the instrumentation and scoring of the piece. Most importantly, I was also able to score the music in a way that incorporates the performer's personal preferences and predispositions, thus suggesting the performative aspects of the embodied creative space.

\section{Closing Remarks}

In an attempt to answer the question "to whom or what do we attribute creative responsibility and agency", Clarke and Doffman $(2017$, p. 2) argued for what they call distributed musical creativity. Examining a broad scope of creative practices encompassing many musical styles and cultures, the authors dispute the traditional boundaries between composers and performers, arguing for interactive, and in turn more collaborative shaping of music making. This approach allows musicians to also shape their own creative developments and their own musical creativity within a more inclusive creative space. Along the same lines, as more recent debates in creative entrepreneurship sug-gest, creative success in any domain does not depend anymore on a sole genius or on the specialization in a single area of interest instead, it is the generalists, and not the specialists, who are becoming poised to be more creative and successful in their career pursuits (Epstein 2019). On that note, an awareness of the embodied creative space and an eagerness to explore its interactive potentialities may further enhance musicians' creative potential.

Much more could be said about the creative experience in music: imagination, inspiration, innovation (Hargreaves et al., 2012), the list could go on; not to mention creative constraints, as well as effects of work life and environment on musical creativity (Amabile et al., 1996). Hopefully the ideas presented in this article may resonate with musicians and scholars alike, thus complementing the existing literature on the topic of musical creativity, as well as providing a different perspective on making music. Building on mounting empirical and conceptual evidence of the importance of psychological contexts in understanding creativity, this article is an ongoing exploration, and as a launching pad for future research.

\section{References}

Amabile, T. R. Conti, H. Coon and M. Corron. (1996). "Assessing the Work Environment for Creativity." The Academy of Management Journal, 39 (5): 1154-1184.

Bach, J. S., Poulin, P. L. and Thieme, C. A. (1994). J.S. Bach's Precepts and principles for playing the thorough-bass or accompanying in four parts: Leipzig, 1738. New York: Oxford Univer-sity Press.

Byrne, D. (2017). How Music Works. New York: Three Rivers Press.

Burnard, P. (2012). Musical Creativities in Practice. New York: Oxford University Press.

Clark, A. (2008). Supersizing the Mind: Embodiment, Action, and Cognitive Extension. New York: Oxford University Press.

Clarke, E. F and M. Doffman, eds. (2017). Distributed Creativity. New York: Oxford University Press. Cook, N. (2017). Music as Creative Practice. New York: Oxford University Press.

Croft, W. and D. A. Cruse. (2004). Cognitive

Linguistics. Cambridge, MA: Cambridge University Press

Cox, A. (2016). Music and Embodied Cognition: Listening, Moving, Feeling, and Thinking. Bloomington, Indiana University Press.

Csikszentmihalyi, M. (1988). "Where is the evolving milieu?" Creativity Research Journal, 1, 60-62.

Csikszentmihalyi, M. (1996). Creativity: The Psychology of Discovery and Invention. New York: HarperPerennial.

Epstein, D. (2019). Range: Why Generalists Triumph in a Specialized World. New York: River-head Books. 
Gardner, H. (2006). Multiple Intelligences: New Horizons in Theory and Practice. New York: Basic Books.

Gregson, P. (2018). Recomposed by Peter Gregson: Bach - The Cello Suites. Berlin, Germany: Deutsche Grammophon, CD.

Hargreaves, D. J., D. Miell and R. A. R. MacDonald, eds. (2009). Musical Imaginations: Multidisciplinary Perspective on Creativity, Performance and Perception. Oxford: Oxford University Press.

Kaufman, J. C., and Sternberg, R. J., eds. (2010). The Cambridge handbook of creativity. New York: Cambridge University Press.

Leman, M. (2008). Embodied Music Cognition and Mediation Technology. Cambridge, MA: The MIT Press.

Locke, P. M and R. McCann, eds. (2015). MerleauPonty: Space, Place, Architecture. Athens, $\mathrm{OH}$ : Ohio University Press.

Mahnkopf, C. (2002). "Theses Concerning Harmony Today" in Polyphony and Complexity, edited by Claus-Steffen Mahnkopf, Frank Cox and Wolfram Schurig. Hofheim: Wolke.
Merleau-Ponty, M. (2013). Phenomenology of Perception. New York: Routledge.

Nagy, Z. (2015). “The Apperception of Musical Creativity: Performance as Ritual, Composition as Self-Realization." Creativity Research Journal: 27(1), 1-8.

Nagy, Z. (2016). "Epigram Variations: for four cellos (2016)”. Liquescence: Music by Zvonimir Nagy. Albany, NY: Albany Records.TROY 1699, CD.

Nagy, Z. (2018). Embodiment of Musical Creativity: The Cognitive and Performative Causality of Musical Composition. Abingdon, UK: Routledge (An Ashgate Book: SEMPRE Series in the Psychology of Music).

Sawyer, K. (2012). Explaining Creativity: The Science of Human Innovation. New York: Oxford University Press.

Shapiro, L., ed. (2017). The Routledge Handbook of Embodied Cognition. New York: Routledge.

Yates, F. A. (1966). The Art of Memory. Chicago: The University of Chicago Press.

Wolff, C. (2000). Johann Sebastian Bach: The Learned Musician. New York: W. W. Norton \& Company. 